\title{
Cessation Pause Quantity
}

National Cancer Institute

\section{Source}

National Cancer Institute. Cessation Pause Quantity. NCI Thesaurus. Code C93528.

A quantity of time that elapses between two repeating activities or events. 